\title{
Türkiye Adresli "Kompost”" Yayınlarının Science Citation Index (SCI) Veri Tabanındaki Etkinliğinin Analizi
}

\author{
Kemal AKTAŞ*, Ayça ERDEM \\ Akdeniz Üniversitesi, Mühendislik Fakültesi, Çevre Mühendisliği Bölümü, Antalya, Türkiye \\ *e-posta: kemalaktas@akdeniz.edu.tr; Tel: +90 (242) 2274400 / 4358
}

\begin{abstract}
Özet: Bu çalışmada, Türkiye adresli kompost çalışmaları Web of Science Core Collection (WoS) veri tabanı kullanılarak analiz edilmiştir. "Compost*" anahtar kelimesi kullanılarak 1970 - 2016 yılları arasında yayınlanan çalışmalar, konu, başlık, özet ve anahtar kelime kategorilerinde aratılmıştır. Elde edilen sonuç Endnote X6'ya aktarılmış ve Microsoft Excel kullanılarak analiz edilmiştir. Veriler, yayın yılları, diğer ülkeler, üniversiteler, araştırma alanları, anahtar kelimeler ve yayın yapılan dergiler gibi farklı açılardan incelenmiştir. 1970 - 2016 yılları arasında, WoS veri tabanında Türkiye'den 334 adet yayın olduğu görülmüştür. Makale en çok tercih edilen yayınlama türüdür. 2000 yılından sonra Türkiye'de ve dünya'da yapılan yayın sayılarında büyük bir artış olmuştur. Türkiye'de en çok yayını sırasıyla On Dokuz Mayıs, Akdeniz ve Çukurova Üniversitelerinde yapılmıştır. En çok tercih edilen dergi Fresenius Environmental Bulletin ve ACTA Horticulturae'dir. Kompost ile ilgili yapılan çalışmaların sırasıyla çevre bilimi, biyoteknoloji, toprak, tarım ve bitki bilimi ile daha çok ilişkili olduğu görülmüştür.
\end{abstract}

Anahtar kelimeler: Bibliyometrik analiz, Katı atık, Kompost, Organik atık, Tarım

\section{Activity Analysis of Turkey Addressed "Compost" Publications in Science Citation Index (SCI) Database}

\begin{abstract}
In this study, Web of Science Core Collection database (WoS) was used to analyze Turkey addressed compost publications. "Compost*" was used as the keyword in topic, title, abstracts and keywords from 1970 to 2016. Results were transferred to Endnote X6 and data was analyzed using Microsoft Excel. The dataset was studied from different perspectives such as publication years, countries, affiliated universities, subject areas, keywords and journals. There are 334 publications in WoS database between 1970 and 2016 from Turkey. Article was by far favorable publication preference. Publications had a great increase after 2000 in Turkey and globally. The most number of publications were contributed from On Dokuz Mayıs, Akdeniz and Cukurova Universities. The most preferred journals were Fresenius Environmental Bulletin and ACTA Horticulturae. Compost studies were found to be more related with the fields of environmental science, biotechnology, soil science, agrology and botanic.
\end{abstract}

Keywords: Bibliometric analysis, Solid waste, Compost, Organic waste, Agriculture

\section{Giriș}

Canlıların aktivelerinden oluşan katı atığın (Tchobanoglous ve ark. 1993) organik kısmından kompost elde edilebilmektedir. Kompostlama, kontrollü bir şekilde bitkisel ya da hayvansal kaynaklı atıkların biyolojik ayrışması sonucu stabil hale gelmesidir. Biyolojik proseslerin de diğer her proseslerde olduğu gibi avantajları ve dezavantajları vardır. Düşük ilk yatırım maliyeti ve işletim giderleri ile düşük çevresel ayak izi olması avantajları iken yavaş bir proses olması ve işletim sürecinin basit olmaması dezavantajlarıdır (Diaz ve ark. 1993).

Türkiye İstatistik Kurumu (TÜİK) verilerine göre Türkiye'de 2014 yılında yaklaşık 28 milyon ton/yıl katı atık toplanmıştır. Toplanan atıkların yaklaşık \%99'u düzenli ve düzensiz depolama tesisine gitmekte iken $\% 0,5$ 'i kompostlama tesisine ve \%0,5'i diğer yöntemlerle bertaraf edilmektedir. Avrupa Birliğindeki 28 ülkenin ortalaması ise \%16 kompostlama ve anaerobik parçalama, \%28 depolama, \%26 yakma, \%28 geri dönüşüm ve $\% 2$ diğer yöntemlerdir. Akdeniz ülkeleri olan İtalya, Portekiz ve İspanya'da durum ise sırasıla; \%32, \%49 ve $\% 58$ depolama ile \%16, \%14 ve \%14 kompostlama ve anaerobik parçalamadır (EUROSTAT 2017). Düzenli depolama, yakma ve kompostlama gibi uygun atık uzaklaştırma yöntemleri AB ülkelerine kıyasla Türkiye'de önemli ölçüde geridedir (Yay 2015). Türkiye'de oluşan katı atığın yaklaşık olarak yarısı organik olup, park ve bahçe atıkları, mutfak ve gıda atıkları ile gıda sanayinden gelen atıklar ile hayvansal atıklardan kompost elde 
edilebilmektedir. Türkiye organik atıklardan kompost üretiminde gelişmiş ülkelerden geride kaldığ görülmektedir. Karbon bakımından zengin bir kaynak olan organik atıkların kompost olarak kullanılarak çevreye etkisi azaltılmalıdır.

Bilimsel yayın trendini incelemekte kullanılan en yaygın yöntemlerden biri bibliyometrik analiz yöntemidir. Bibliyometrik analiz yönteminin farklı tanımları vardır. Temel olarak yayınlanan çalışmaların ve atıflarının kantitatif analizi ve istatistiksel hesaplama metodudur. Bu sebeple bilimsel araştırma trendlerini incelemek için kullanılmıştır (Bayer ve Folger 1966; Garfield 1970; Altman ve Gorman 1998; Li ve Ho 2008). Kompost üzerine bibliyometrik anlamda tek bir çalışma (Chen ve ark 2014) bulunmakta iken katı atıklar üzerine çalışmalar (Fu ve ark 2010; Ma ve ark 2011; Yang ve ark 2013; Liu ve ark 2014; Zyoud ve ark 2015; Chen ve ark 2015) az olsa da bir artış göstermektedir.

Bu çalışmanın amacı, WoS veri tabanındaki 1970-2016 yılları arasında Türkiye adresli yayınlanan ve özet, başlık ve anahtar kelimelerinde "kompost" kelimesi geçen çalışmaları incelemek. Veriler, yayın yılları, diğer ülkeler, üniversiteler, araştırma alanları, anahtar kelimeler ve yayın yapılan dergiler incelenerek analiz edilerek Türkiye'nin dünya literatüründeki yeri tespit edilmeye çalışılacaktır.

\section{Materyal ve Metot}

Bibliyometrik yöntem ile WoS veri tabanından elde edilen yayınlar incelenmiştir. Türkiye adresli, 1970 - 2016 yılları arasında yayınlanan ve "compost*" kelimesinin başlıkta, özette ve anahtar kelimelerin içinde geçtiği çalışmalar elde edilmiştir. WoS Core Collection veri tabanı olarak kullanılmıştır. İlgili arama sonunda elde edilen tüm yayınlar Endnote X6'ya aktarılmış ve Microsoft Excel kullanılarak analiz edilmiştir. Yayın yılları, diğer ülkeler, üniversiteler, araştırma alanları, anahtar kelimeler ve yayın yapılan dergiler incelenerek içerik analizi uygulanmıştır.

\section{Bulgular}

WoS veri tabanında yapılan araştırma sonucunda 1970-2016 yıllarına ait Türkiye adresli 334 yayın olduğu görülmüştür. En çok tercih edilen yayın şekli 294 makale ve daha sonra 44 bildiri gelmektedir. Türkiye'de kompost ile ilgili ilk yayın 1978'de Höfner ve arkadaşları tarafından Ege Üniversitesi adresli olarak yapılmıştır. Dünya'da o yıla kadar kompost ile ilgili belirlenen arama kriterlerinde 783 çalışma yayınlanmıştır. Şekil 1'de Türkiye ve dünya'daki yayınların yıllara göre dağılımı verilmektedir.

Anahtar kelimesi analizinde kompost çalışmalarının en çok "gübre" ve "arıtma çamuru" son yıllarda ise "toprak" ve "ağır metaller" konularıyla ilgili oldukları görülmektedir (Chen ve ark 2014).

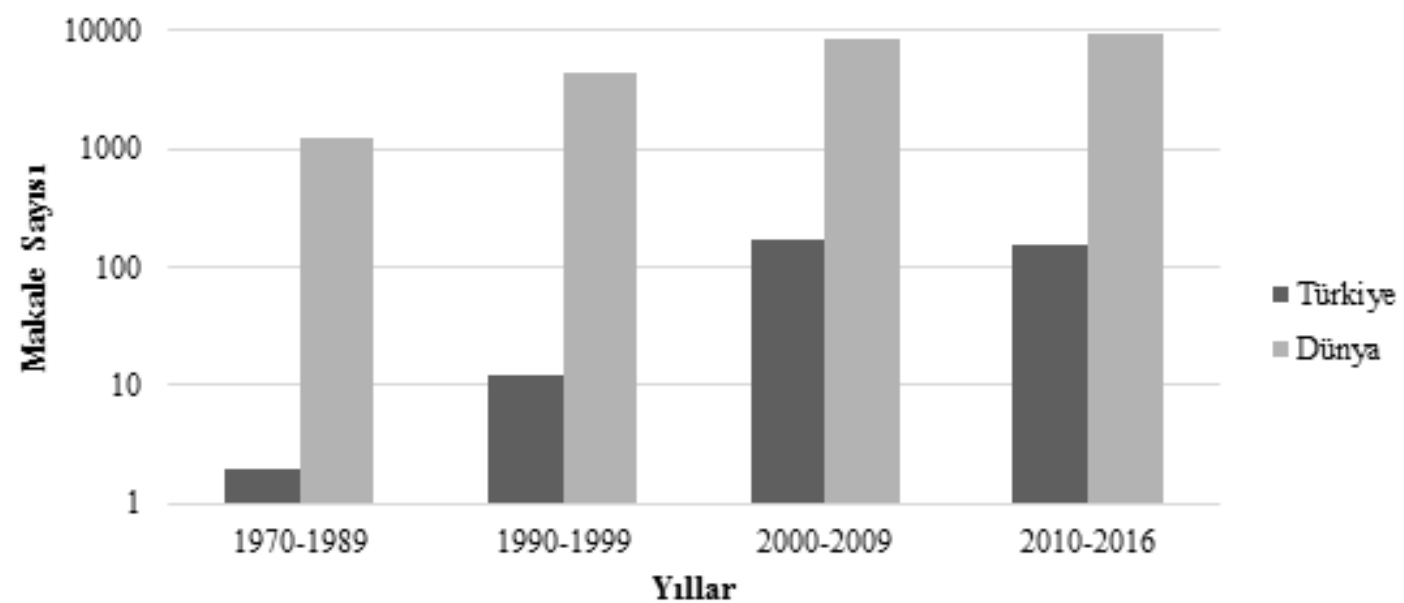

Şekil 1. Yıllara göre Türkiye ve Dünya'daki yayınların dağılımı.

Türkiye'de yapılan çalışmaların niceliğini kıyaslamak adına aynı arama kriterlerinde en çok yayın yapan diğer ülkeler de araştırılmıştır. Amerika Birleşik Devletleri (ABD) 4518 yayın ile açık ara en çok yayın yapan ülke konumundadır. ABD’yi sırasıyla İspanya (1762), Çin (1673) ve Kanada (1223) takip etmektedir. Şekil 2'de ülkelere göre yayınlanan çalışmaların dağılımları görülmektedir. Türkiye 334 çalışma ile en çok yayın yapan 16 . ülke konumundadır. 


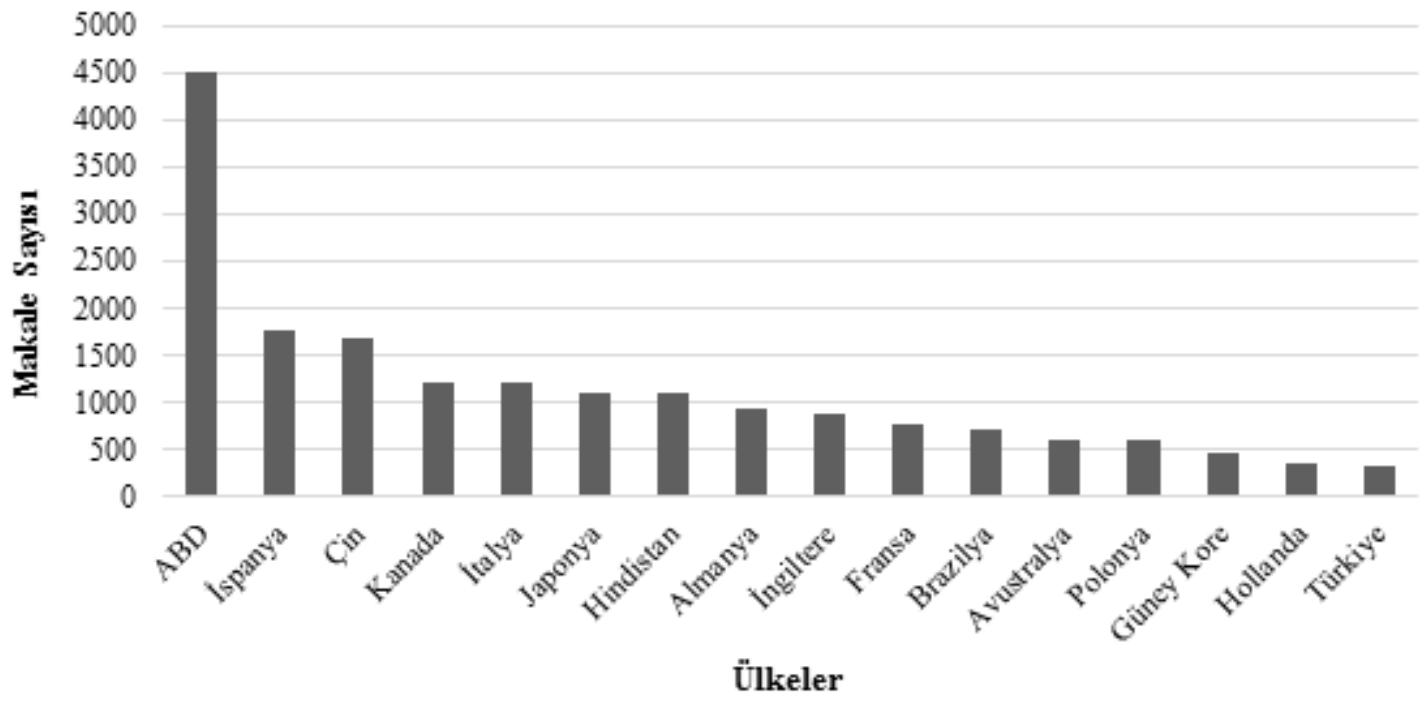

Şekil 2. Ülkelere göre yayınlanan çalışmaların dağılımları.

Üniversiteler bazında Ohio Devlet Üniversitesi, Florida Üniversitesi, Penn Devlet Üniversitesi gibi Amerikan Üniversiteleri dünya kompost literatürüne öncülük etmektedir. Türkiye'de ise sırasıyla On Dokuz Mayıs Üniversitesi (26 yayın), Akdeniz Üniversitesi (25 yayın) ve Çukurova Üniversitesi (24 yayın) en çok çalışma yayınlayan üniversitelerdir. Şekil 3 ’te üniversitelere göre yayınlanan çalışmaların dağılımları verilmektedir.

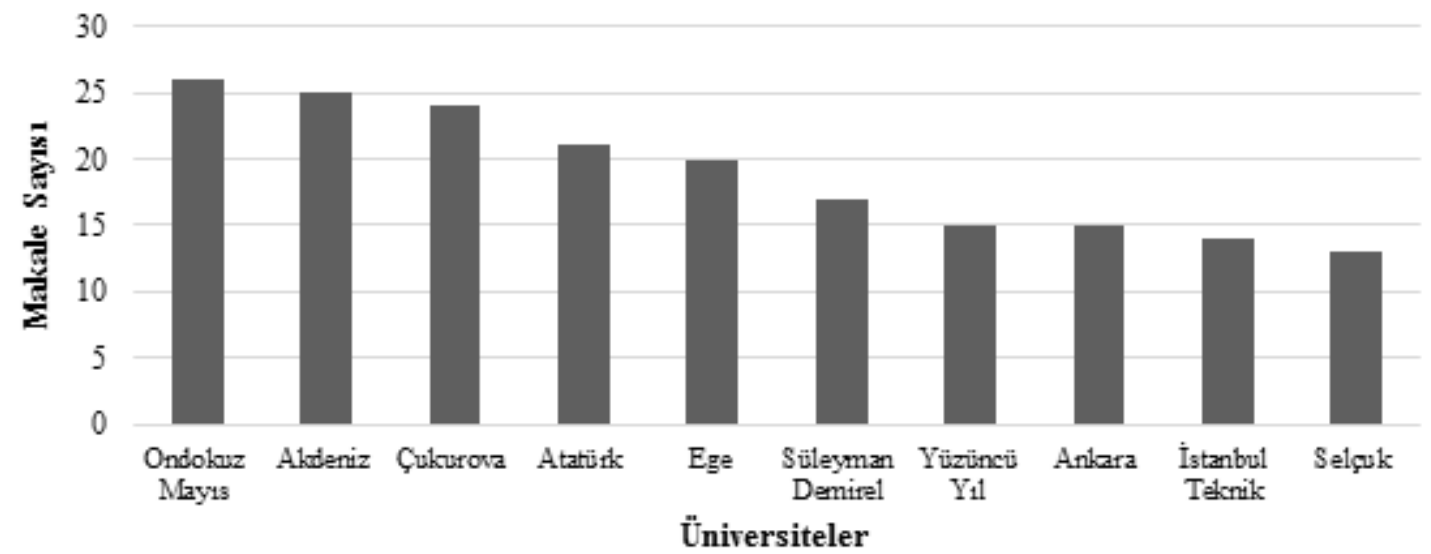

Şekil 3. Üniversitelere göre yayınlanan çalışmaların dağılımları.

Türkiye adresli çalışmaların genellikle düşük etki faktörlü dergilerde yayınlandığı gözlenmektedir. Yayın yapılan dergiler arasında Bioresource Technology (15 yayın) dergisi etki faktörü 5,651 ile en yüksek etki faktöre sahip tek dergi olarak görülmektedir. En fazla yayının yer aldığı Fresenius Environmental Bulletin (25 yayın) ve diğer dergilerin etki faktörü 1 'in altında kalmaktadır. Bu durum yapılan çalışmaların yetersiz olmasının yanı sıra etkin değerliği yüksek çalışmaların üretilmesinde zorluklar yaşandığını göstermektedir. Şekil 4'de yayınlanan makalelerin dergilere göre dağılımı gösterilmektedir. 


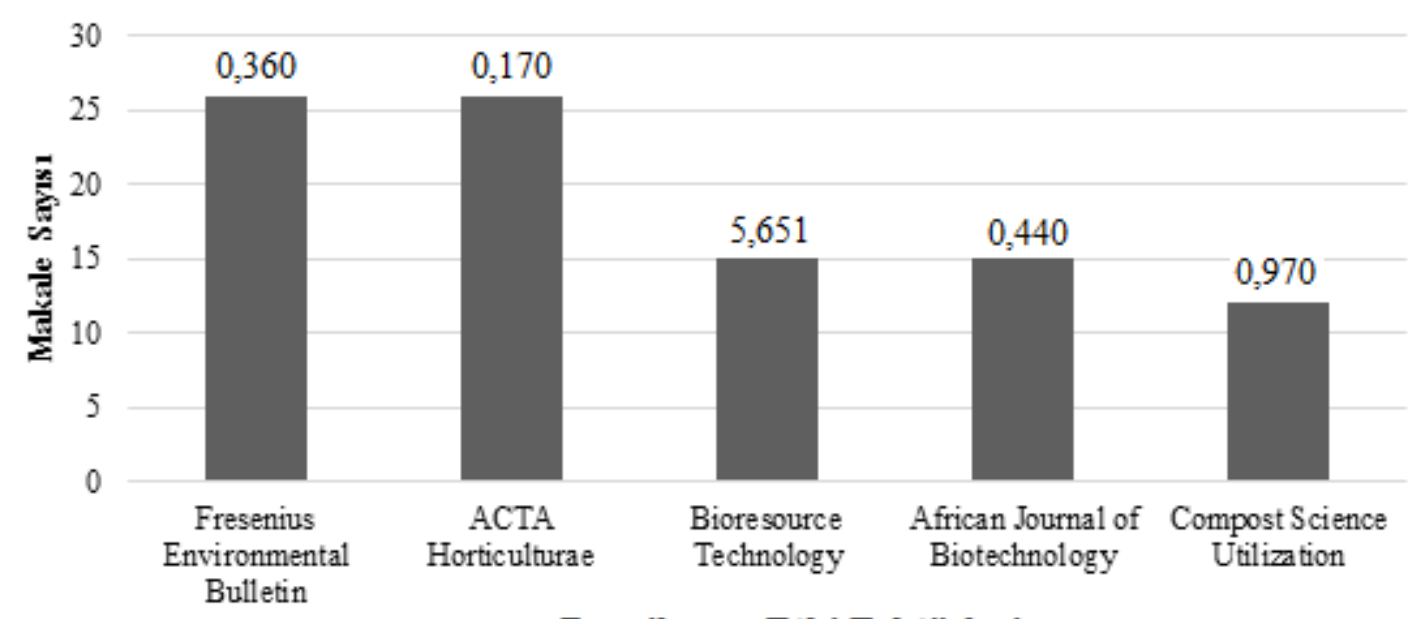

\section{Dergiler ve Etki Faktörleri}

Şekil 4. Yayınlanan makalelerin dergilere göre dağılımı.

\section{Tartışma ve Sonuç}

1970 ile 2016 yılları arasında kompost ile alakalı 334 çalışmalar elde edilmiştir. Türkiye'den yayınlanan bu çalışmaların büyük kısmı makale olarak yayınlanmıştır. Bunu bildiriler, derlemeler ve düzeltmeler takip etmektedir. Bu çalışmalar sırasıyla İngilizce (322), Türkçe (9), Almanca (2) ve Çekçe (1) olarak yayınlanmıştır. Science Citation Index (SCI) dergilerinde baskın dilin İngilizce olduğu görülmektedir. Dünya genelinde ilk çalışma 1970'de yapılırken Türkiye 1978'de SCI literatürüne kompost alanında katkıda bulunmuş̧tur.

$\mathrm{Bu}$ çalışma, WoS veri tabanından elde edilen veriler incelenerek Türkiye'nin kompost literatürüne katkısı hakkında bilgi vermektedir. Bu çalışmadan elde edilen sonuçlar şöyledir:

- 2000 yılından sonra çalışmalar hız kazanmaktadır.

- Türkiye kompost alanındaki SCI yayınlarında gelişmiş ülkelerin gerisindedir.

- Türkiye'de yapılan çalışmalara tarım yapılan büyük kıyı şehir Üniversitelerinin öncülük ettiği görülmektedir.

- Türkiye'de ki kompost çalışmaları genellikle etki faktörü 1'in altındaki dergilerde yayınlanmaktadır.

- SCI yayınlarında ki ana dil İngilizcedir.

Bibliyometrik analiz yapılan çalışmaların içeriğinden daha çok istatistiksel olarak kapsamlı veri tabanı oluşturmayı hedefler. Atıflar, yazar ve sayfa sayıları gibi verileri bir istatistiksel model aracığıyla anlamlı hale getirir. Bu makale, Türkiye'den kompost alanında yayınlanan SCI çalışmalarının genel durumu göstermektedir, istatistiksel veriler için detaylı bir bibliyometrik analize ihtiyaç duyulmaktadır.

\section{Kaynaklar}

Altman KG, Gorman GE (1998). The usefulness of impact factors in serial selection: A rank and mean analysis using ecology journals. Library Acquisitions: Practice and Theory, 22: 147-159.

Bayer AE, Folger J (1966). Some correlates of a citation measure of productivity in science. Sociology of Education, 39: 381-390.

Chen H, Jiang W, Yang Y, Man X, Tang M (2015). A bibliometric analysis of waste management research during the period 1997-2014. Scientometrics, 105: 1005-1018.

Chen H, Yang Y, Zhou J, Yang Y, Jiang W (2014). Global trends of compost research from 1997 to 2012: A bibliometric analysis based on SCI database. Asian Journal of Chemistry, 26 (16): 5242-5248.

Diaz FL, Savage MG, Eggerth LL, Golueke GC (1993). Composting and recycling municipal solid waste. Lewis, Florida, $296 \mathrm{s.}$

Fu H, Ho Y, Sui Y, Li Z (2010). A bibliometric analysis of solid waste research during the period 1993-2008. Waste Management, 30: 2410-2417.

Garfield E (1970). Citation indexing for studying science. Nature, 227: 669-671. 
Höfner W, Kovanci I, Hakerlerler H (1978). Influence of compost and Fe-compounds on the uptake of Fe, Zn and $\mathrm{Mn}$ by sunflower and maize in pot experiments. Journal of Plant Nutrition and Soil Science, 141 (5): 547-551.

Li Z, Ho YS (2008). Use of citation per publication as an indicator to evaluate contingent valuation research. Scientometrics, 75: 97-110.

Liu A, Fu H, Li S, Guo Y (2014). Comments on "Global trends of solid waste research from 1997 to 2011 by using bibliometric analysis”. Scientometrics, 98: 767-774.

Ma H, Ho Y, Fu H (2011). Solid waste related research in Science Citation Index Expanded. Archives of Environmental Science, 5: 89-100.

Statistical office of the European Union (EUROSTAT) (2017). Waste statistics for 2014 http://ec.europa.eu/euro stat/tgm/refreshTableAction.do?tab=table\&plugin=1\&pcode=tsdpc240\&language $=$ en (Erişim tarihi: 20.06.2017).

Tchobanoglous G, Theisen H, Vigil AS (1993). Integrated solid waste management engineering principles and management issues. McGraw Hill, New Jersey, 949 s.

Türkiye İstatistik Kurumu (TÜİK) (2014) yılı Belediye katı atı istatistikleri. http://www.tuik.gov.tr/PreTablo.do?alt_id=1019 (Erişim tarihi: 20.06.2017).

Yang L, Chen Z, Liu T, Gong Z, Yu Y, Wang J (2013). Global trends of solid waste research from 1997 to 2011 by using bibliometric analysis. Scientometrics, 96: 133-146.

Yay ESA (2015). Application of life cycle assessment (LCA) for municipal solid waste management: A case study of Sakarya. Journal of Cleaner Production, 94: 284 - 293.

Zyoud HS, Al-Jabi WS, Sweileh MW, Al-Khalil S, Zyoud HS, Sawalha FA, Awang R (2015). The Arab world's contribution to solid waste literature: a bibliometric analysis. Journal of Occupational Medicine and Toxicology, DOI 10.1186/s12995-015-0078-1. 